\title{
Emerging evidence and recent controversies in diverticulitis: a 5-year review
}

\author{
Marina Affi Koprowskia, Arthur Affleck ${ }^{a}$, Vassiliki Liana Tsikitis ${ }^{b}$ \\ Oregon Health and Science University, Portland, OR, USA
}

\begin{abstract}
Diverticulitis is a common gastrointestinal disease that still garners significant attention and study because of its heterogeneity in presentation and outcome. We provide a review of the newest and most controversial topics in diverticulitis. Recent discoveries on the influence of diet and other environmental risk factors are discussed, showing how the epidemiology of the disease process is shifting away from what was previously felt to be a disorder primarily limited to older western populations. Interestingly, as has long been suspected, genetic mutations and variations associated with the development of diverticulitis are being discovered and are summarized here. The data for non-operative and outpatient management of diverticulitis are reviewed, as are pharmacologic agents studied for use in the secondary prevention of diverticulitis. Lastly, we present controversies in the surgical treatment of diverticulitis. This review will provide a synopsis of the last 5 years of literature relating to diverticulitis.
\end{abstract}

Keywords Diverticulitis, epidemiology, etiology, management

Ann Gastroenterol 2021; 34 (6): 1-9

\section{Introduction}

Despite the longtime prevalence of diverticulitis as one of the most common gastrointestinal diseases in both the inpatient and outpatient setting, its etiology, prevention, and treatment remain hotly contested. Once viewed as a disorder of primarily older people in western populations, diverticulitis has rapidly increased its presence in all age groups worldwide, prompting researchers to reexamine the pathophysiology of the disease process [1-3]. Clinicians continue to push the envelope with novel approaches to management, from avoiding antibiotics for uncomplicated cases to identifying subsets of patients with complicated diverticulitis who may not require an operation. Here, we review the most recent literature on a wide array of topics in diverticulitis, with an emphasis on publications within the last 5 years.

${ }^{a}$ Department of Surgery (Marina Affi Koprowski, Arthur Affleck); ${ }^{b}$ Division of Gastrointestinal Surgery, Department of Surgery (Vassiliki Liana Tsikitis), Oregon Health and Science University, Portland, OR, USA

\section{Conflict of Interest: None}

Correspondence to: Vassiliki Liana Tsikitis, MD, MBA, MCR, Professor and Division Head, Division of General and Gastrointestinal Surgery, 3181 SW Sam Jackson Park Rd, Mail Code: L-223, Portland, OR 97239, USA, e-mail: tsikitis@ohsu.edu

Received 14 June 2021; accepted 27 September 2021; published online 11 November 2021

DOI: https://doi.org/10.20524/aog.2021.0677

\section{Etiology of diverticulitis}

\section{Influence of diet}

Diverticulitis has long been attributed to an insufficient intake of dietary fiber. Recently, studies have attempted to elucidate the amount and type of fiber that affects diverticulitis risk and to identify any additional dietary risk factors. Recent analyses of women from the Nurses' Health Study have found that, specifically, the top quintile of dietary fiber consumption is associated with a lower incidence of diverticulitis [1]. Moreover, for the first time, consumption of whole fruits (particularly apple, pear, and prune) and cereal fibers has been linked to a lower incidence of diverticulitis, while vegetable intake may not be [1].

Similar studies of men from the Health Professionals FollowUp Study demonstrated that a "prudent" diet (consisting mostly of fruits, vegetables, whole grains, legumes, poultry, and fish) was associated with a lower incidence of diverticulitis compared to a traditional western diet [2]. Analysis of this cohort also showed that recent diets (within 1-4 years of diverticulitis diagnosis) had more of an association with diverticulitis than chronic consumption of any diet, implying in a novel way that changes in diet may have an effect in the short term. Body mass index (BMI) was reported to be unassociated with the risk of diverticulitis when dietary habits were controlled for. An additional study of the same cohort found that the risk of diverticulitis was higher with unprocessed red meat when compared to processed red meat, and that the risk plateaued after 6 servings of red meat a week [3]. Diet-related inflammatory 
serum markers (C-reactive protein, interleukin-6, and tumor necrosis factor) have also been correlated with incident diverticulitis within this cohort [4].

\section{Influence of additional environmental factors}

A comparison of smoking vs. non-smoking patients hospitalized with diverticulitis found no difference in mortality, though smokers did have a higher incidence of numerous complications (including lower gastrointestinal bleed, sepsis, peritonitis, and need for colectomy) as well as longer length of hospital stay [5]. In another Nurses' Health Study paper by $\mathrm{Ma}$ et al, the risk of diverticulitis was linearly associated with BMI, and weight gain since early adulthood was also associated with an increased incidence of diverticulitis, even when controlling for diet (red meat and fiber intake), physical activity, smoking status, and alcohol consumption [6].

Combined analysis of a generally "healthy lifestyle" (defined as red meat intake of $<51 \mathrm{~g} /$ day, fiber intake among the highest $40 \%$ of the cohort, vigorous physical activity among the highest $50 \%$ of the cohort, BMI under $25 \mathrm{~kg} / \mathrm{m}^{2}$, and never smoker) was altogether inversely linearly associated with incident diverticulitis risk in a recent analysis of the Health Professionals Follow-Up Study [7]. This analysis also noted that the use of non-steroidal anti-inflammatory drugs was associated with incident diverticulitis in this population, a topic which has not otherwise been studied recently. A large population study of over 18,000 admissions for acute diverticulitis in the UK, Australia and the United States found a peak in the summer months in all countries [8].

\section{Genetic contributions}

Perhaps the most groundbreaking development in diverticulitis etiology research is the recent identification of genetic associations with the diverticulosis and diverticulitis phenotypes. Though "garden variety" diverticulitis is attributed to a combination of genetic and environmental factors, as are most Western diseases, some heritable factors have been identified in twin studies and genetic sequencing studies, particularly in severe cases $[9,10]$. Connective tissue, neuromuscular and epithelial-associated genetic mutations have been implicated, probably as a result of suspicion arising from the noted associations between diverticulitis and Ehlers-Danlos or Marfan syndromes, incisional hernias, aortic aneurysms, rectal prolapse and other such disorders [11].

Early onset and severe diverticulitis have been linked to LAMB4 and TNFSF15 mutations, which encode for laminin proteins and the tumor necrosis factor family, respectively $[12,13]$. Specifically, TNFSF15 mutation has been implicated in the development of surgical diverticulitis [13]. One large genome-wide sequencing study was initially completed in an Icelandic population and identified ARHGAP15, FAM155A, and $C O L Q$ as single nucleotide polymorphisms associated with diverticulitis [14]. These same mutations were later validated in Danish and UK populations [15]. The mutations affect 99 identified genes, with functions ranging from regulation of neutrophils, calcium transporters for the interstitial cells of Cajal, and components of the elastin protein [16]. Additional phenome-wide association studies were undertaken that showed genetic enrichment of mesenchymal stem cells and other connective cell and tissue types. Patients with a family history of diverticulitis have also been noted to be at higher risk for recurrent and complicated episodes, though the potential genetic underpinning of this finding has not been specifically investigated [17]. The milieu of pathophysiologic factors that may cause diverticulitis is summarized in Fig. 1.

\section{Management of uncomplicated diverticulitis}

\section{Need for antibiotics}

The need for antibiotics during an uncomplicated episode of diverticulitis has been challenged for at least a decade. There have been several well-designed randomized controlled trials (RCTs) providing Level I evidence and informing numerous society recommendations on the omission of antibiotics in uncomplicated diverticulitis. However, this movement has not yet gained such significant traction in American populations as it has in the European populations in which it was originally studied.

The AVOD trial was initially published in 2012, and followed Swedish patients with uncomplicated diverticulitis who were randomized to treatment with or without antibiotics [18]. Neither the initial study, nor the recent longterm follow up published in 2019, suggested any differences in outcomes between the 2 groups [19]. At a median follow up of 11 years, there were similar rates of recurrence, surgery, and development of colorectal cancer (CRC) in both groups.

The Dutch Diverticular Disease (3D) Study group published the DIABOLO RCT in 2017 with similar findings suggesting the safety of avoiding antibiotic therapy in patients with uncomplicated diverticulitis. No significant differences were found at 6 months in days to recovery, recurrence, readmission rates or mortality, among other endpoints [20]. Their 24-month follow up published in 2018 also supported this conclusion [21].

Despite solid evidence refuting the routine use of antibiotics in uncomplicated diverticulitis, controversy remains. A 2018 joint survey of members of the Society of American Gastrointestinal and Endoscopic Surgeons and the European Association of Endoscopic Surgery found that only 26\% of them endorsed a trial of treatment without antibiotics, and half of them still would not practice this society recommendation [22].

\section{Restriction of diet during acute flare}

It has long been common practice to restrict fiber intake and pursue conservative diets during an episode of diverticulitis; 


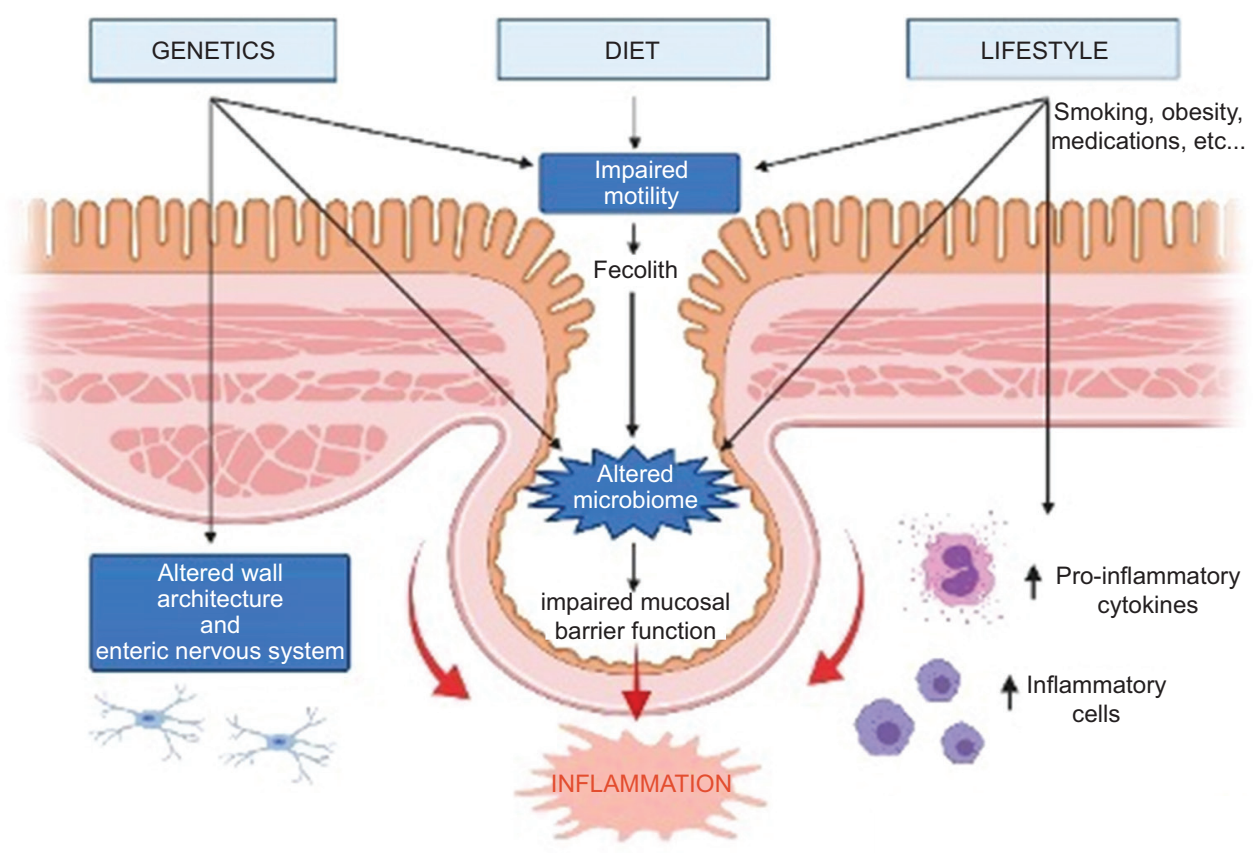

Figure 1 Pathophysiology of diverticulitis. The pathogenetic mechanisms leading to diverticulitis are multifactorial, including genetic, dietary, and environmental factors, ultimately resulting in inflammation of one or more colonic diverticula

however, there is little evidence to support this practice, which has come under scrutiny in recent years. A recent systematic review published in 2018 included 5 studies investigating the role of dietary fiber modification during an acute flare. The 3 observational studies and 2 RCTs were all considered very low quality, but did not suggest a difference in clinical outcomes based on diet during treatment of acute diverticulitis [23].

\section{Preventing recurrence of diverticulitis (secondary prevention)}

\section{Rifaximin}

Rifaximin is a poorly absorbed drug that provides antimicrobial and anti-inflammatory benefits in the gut. No systematic review or meta-analysis has been published on the topic of rifaximin for diverticulitis since 2011, when it was demonstrated that rifaximin significantly reduced symptoms of diverticulitis at 1 year [24]. Rifaximin is more commonly used in Europe, but its cost is often prohibitive in the United States. Recent studies have again attributed symptomatic and quality-of-life benefits to rifaximin following an episode of uncomplicated diverticulitis, but its role in secondary prevention and appropriate dosing (continuous vs. cyclic) have yet to be defined [25].

\section{Mesalamine}

A 2017 Cochrane review of 7 RCTs attempted to investigate the efficacy of mesalamine in the secondary prevention of diverticulitis [26]. They did not identify a difference in the outcome of recurrent diverticulitis with the use of mesalamine, but noted that the data to support this conclusion is very low quality and the studies were significantly heterogeneous. Though several additional systematic reviews with conflicting evidence exist, just one reports a benefit from the use of mesalamine when compared to placebo or other interventions [27-29].

\section{Probiotics}

The presumptive purpose of probiotics is to restore healthy intestinal microbiota and prevent a plethora of gastrointestinal diseases. Based on the results of a systematic review published in 2016, there is insufficient evidence to recommend their use in diverticulitis [30]. However, some studies show trends towards improvement in symptoms and recurrence following symptomatic diverticular disease [31]. No additional endpoints have been studied. No societies yet endorse the use of probiotics, and further studies are warranted on this subject.

\section{Management of complicated diverticulitis}

\section{Need for hospitalization}

Two recent systematic reviews and meta-analyses support the safety of treating patients with uncomplicated diverticulitis in the outpatient setting, though patients with significant comorbidities or immunosuppression are often excluded [32,33]. Just 2 studies to date examining outpatient therapy for diverticulitis have included 
patients with any complicated disease. Joliat et al included stable patients with mild complicated diverticulitis (defined as abscess $<4 \mathrm{~cm}$ or pneumoperitoneum $<2 \mathrm{~cm}$ ) in their retrospective outpatient study and determined it was safe to manage this group as outpatients with close follow up [34]. Sirany et al also retrospectively analyzed patients with diverticulitis and found a very small subset $(n=6)$ who had complicated disease and were discharged home from the emergency department with a $50 \%$ readmission rate, thus preventing the authors from drawing any conclusions about the safety of managing patients with complicated disease in the outpatient setting [35]. Further work is needed to determine which subgroups of patients with complicated diverticulitis may be appropriate for outpatient care.

\section{Non-operative therapy}

Non-operative and/or percutaneous management of complicated diverticulitis has long been favored for stable patients. Internationally, mixed guidelines exist on the role of elective resection following non-operative treatment of complicated disease. Generally, the literature supports the fact that patients who do not have resections following the treatment of complicated disease will go on to have recurrent episodes, if not ongoing smoldering symptoms [36]. However, additional outcomes are less well studied.

A recent retrospective review of Swiss and Scottish patients from 2005-2015 attempted to answer the question of whether elective interval resection for initially non-operatively managed complicated diverticulitis is associated with adverse outcomes [37]. While $25 \%$ of Swiss and $5 \%$ of Scottish patients underwent interval resection, the authors found no difference in the rates of emergency surgical intervention or death between the populations ( $5 \%$ in both groups). The authors challenged the routine recommendation of prophylactic surgery following nonoperative management of complicated diverticulitis, as is the current practice according to German and American guidelines. An RCT is needed to determine the long-term safety of non-operative treatment of complicated diverticulitis.

\section{Hartmann procedure vs. primary anastomosis}

Perhaps the greatest challenge to dogma in the surgical treatment of diverticulitis was the proposition that a sigmoid colectomy with colostomy is unnecessary in many cases of complicated disease. The long-awaited publication of the DIVA arm of the Ladies trial in 2019 was referred to by some as "the end of the Hartmann's era for perforated diverticulitis” [38,39]. This was a randomized superiority trial performed at multiple sites in Europe, including 133 patients $<85$ years of age with peritonitis and Hinchey III or IV diverticulitis. They were randomized to a Hartmann's procedure or sigmoidectomy with primary anastomosis, with diverting ileostomy left to the discretion of the surgeon (performed in 63\% of cases). The study found a significantly better stoma-free survival at 12 months (number needed to treat $=4$ ) in the primary anastomosis group, with no differences between the 2 groups in short-term morbidity or mortality. A cost-effectiveness study was subsequently published that also favors primary anastomosis [40]. Long-term data are not yet available but are eagerly anticipated.

Uptake of this trend is less accepted in the United States, partly because of the Ladies trial location and patient composition. Cauley et al state that, while use of primary anastomosis with diverting ileostomy for emergent or urgent sigmoidectomy has doubled in the US since the turn of the century, overall use remains low (with $>90 \%$ of patients still undergoing a Hartmann's procedure), while there are significantly higher in-hospital mortality rates in the diversion group [41]. However, this study was analyzed from a large, national dataset that was unable to provide granular patient information. While it provides valuable information on the current state of practice in the United States, it lacks the strength of an RCT.

\section{Laparoscopic peritoneal lavage}

Laparoscopic peritoneal lavage for purulent peritonitis was a trendy topic for some time during the last 2 decades, though it has been less eagerly embraced following several publications, including the LOLA arm of the above-mentioned Ladies trial [42]. This group of hemodynamically and nonimmunosuppressed patients aged $<85$ years with purulent peritonitis was randomized to laparoscopic lavage vs. Hartmann's procedure vs. primary anastomosis, but the study was terminated early because of safety concerns (primarily need for surgical reintervention during admission). Ultimately, 12-month follow up of the 90 enrolled patients did not show any significant difference in morbidity or mortality.

Similarly, the 2015 SCANDIV trial randomized almost 200 patients with perforated diverticulitis to laparoscopic peritoneal lavage or colon resection, and found no reduction in postoperative complications in the lavage group, with significantly higher rates of reoperation and 4 missed cases of sigmoid cancer [43,44]. The 5-year follow up published in 2021 demonstrated higher stoma rates in the resection group, but significantly higher rates of recurrent diverticulitis in the lavage group ( $21 \%$ vs. $4 \%$ ), such that $30 \%$ ultimately required sigmoid resection [45].

The DILALA trial is the only major RCT to show reoperation rate, morbidity, mortality and cost benefits to laparoscopic lavage, in both the initial analysis published in 2016 and the 2-year follow up published in 2018, but at this point considerable doubt has been cast on the utility and safety of this minimally invasive alternative [46-48]. From the several systematic reviews and metaanalyses on the topic, the evidence is conflicting, and the approach has not been widely and routinely incorporated [49-53].

A summary of recent landmark trials on the surgical therapy of diverticulitis, including the topics of Hartmann procedure vs. primary anastomosis and laparoscopic peritoneal lavage, is provided in Table 1. Additionally, Figure 2 shows a general framework for the treatment of uncomplicated vs. complicated diverticulitis; however, as has been discussed, 
Table 1 Recent landmark randomized controlled trials in surgery for diverticulitis

\begin{tabular}{|c|c|c|c|c|c|c|c|}
\hline $\begin{array}{l}\text { Study, } \\
\text { year [Ref.] }\end{array}$ & Location & ARM & $\begin{array}{l}\text { Included } \\
\text { patients }\end{array}$ & Intervention & Primary endpoint & $\begin{array}{l}\text { Secondary } \\
\text { endpoints }\end{array}$ & Conclusion \\
\hline $\begin{array}{l}\text { Ladies, } \\
2019[38]\end{array}$ & $\begin{array}{l}\text { Belgium, } \\
\text { Italy, } \\
\text { Netherlands }\end{array}$ & DIVA & $\begin{array}{l}\text { Perforated } \\
\text { diverticulitis } \\
\text { and fecal } \\
\text { peritonitis }\end{array}$ & $\begin{array}{l}1: 1 \text { to } \mathrm{HP} \text { or } \\
\text { resection } \\
+ \text { anastomosis }\end{array}$ & $\begin{array}{l}\text { 12-month stoma-free } \\
\text { survival }\end{array}$ & $\begin{array}{l}\text { Short-term } \\
\text { morbidity and } \\
\text { mortality }\end{array}$ & $\begin{array}{l}\text { 12-month } \\
\text { stoma-free survival } \\
\text { significantly better for } \\
\text { resection+anastomosis } \\
\text { group; no significant } \\
\text { differences in } \\
\text { short-term morbidity } \\
\text { or mortality }\end{array}$ \\
\hline $\begin{array}{l}\text { Ladies, } \\
2015 \text { [42] }\end{array}$ & $\begin{array}{l}\text { Belgium, } \\
\text { Italy, } \\
\text { Netherlands }\end{array}$ & LOLA & $\begin{array}{l}\text { Perforated } \\
\text { diverticulitis } \\
\text { and } \\
\text { purulent } \\
\text { peritonitis }\end{array}$ & $\begin{array}{l}\text { 2:1:1 to } \\
\text { laparoscopic } \\
\text { lavage, HP, or } \\
\text { resection } \\
\text { +anastomosis }\end{array}$ & $\begin{array}{l}\text { Composite of major } \\
\text { morbidity and } \\
\text { mortality within } 12 \\
\text { months }\end{array}$ & N/A & $\begin{array}{l}\text { Terminated early due } \\
\text { to event rate in lavage } \\
\text { group; laparoscopic } \\
\text { lavage not superior to } \\
\text { sigmoidectomy }\end{array}$ \\
\hline $\begin{array}{l}\text { SCANDIV, } \\
2015 \text { [44] }\end{array}$ & $\begin{array}{l}\text { Sweden and } \\
\text { Norway }\end{array}$ & N/A & $\begin{array}{l}\text { Suspected } \\
\text { perforated } \\
\text { diverticulitis } \\
\text { with free air } \\
\text { undergoing } \\
\text { emergency } \\
\text { surgery }\end{array}$ & $\begin{array}{l}\text { 1:1 laparoscopic } \\
\text { lavage or } \\
\text { resection }\end{array}$ & $\begin{array}{l}\text { Severe postoperative } \\
\text { complications } \\
\text { (Clavien-Dindo>IIIa) } \\
\text { within } 90 \text { days }\end{array}$ & $\begin{array}{l}\text { Other } \\
\text { postoperative } \\
\text { complications, } \\
\text { reoperations, } \\
\text { operating } \\
\text { time, } \\
\text { postoperative } \\
\text { stay, quality } \\
\text { of life }\end{array}$ & $\begin{array}{l}\text { Laparoscopic lavage } \\
\text { did not reduce severe } \\
\text { complications and led } \\
\text { to worse outcomes in } \\
\text { secondary outpoints, } \\
\text { including } 4 \text { cases } \\
\text { of missed sigmoid } \\
\text { cancer }\end{array}$ \\
\hline $\begin{array}{l}\text { DILALA, } \\
2016 \text { [46] }\end{array}$ & $\begin{array}{l}\text { Sweden and } \\
\text { Denmark }\end{array}$ & N/A & $\begin{array}{l}\text { Perforated } \\
\text { diverticulitis } \\
\text { with } \\
\text { purulent } \\
\text { peritonitis }\end{array}$ & $\begin{array}{l}\text { 1:1 laparoscopic } \\
\text { lavage or HP }\end{array}$ & $\begin{array}{l}\text { Morbidity and } \\
\text { mortality within } 12 \\
\text { weeks }\end{array}$ & N/A & $\begin{array}{l}\text { Morbidity and } \\
\text { mortality did not } \\
\text { differ; shorter } \\
\text { operating time and } \\
\text { length of stay with } \\
\text { laparoscopic lavage }\end{array}$ \\
\hline $\begin{array}{l}\text { DIRECT, } \\
2017 \text { [64] }\end{array}$ & Netherlands & N/A & $\begin{array}{l}\text { Recurrent } \\
\text { diverticulitis } \\
\text { or persistent } \\
\text { abdominal } \\
\text { complaints } \\
\text { after a single } \\
\text { episode }\end{array}$ & $\begin{array}{l}3: 3 \text { conservative } \\
\text { management } \\
\text { or elective } \\
\text { laparoscopic } \\
\text { sigmoidectomy }\end{array}$ & GIQLI at 6 months & N/A & $\begin{array}{l}\text { Significantly higher } \\
\text { quality of life in } \\
\text { resection group } \\
\text { with higher risk of } \\
\text { complication }\end{array}$ \\
\hline $\begin{array}{l}\text { LASER, } \\
2021 \text { [67] }\end{array}$ & Finland & N/A & $\begin{array}{l}\text { Recurrent, } \\
\text { complicated, } \\
\text { or persistent } \\
\text { painful } \\
\text { diverticulitis }\end{array}$ & $\begin{array}{l}\text { 1:1 conservative } \\
\text { management } \\
\text { or elective } \\
\text { laparoscopic } \\
\text { sigmoidectomy }\end{array}$ & GIQLI at 6 months & N/A & $\begin{array}{l}\text { Significantly higher } \\
\text { quality of life in } \\
\text { resection group with } \\
10 \% \text { risk of major } \\
\text { complication }\end{array}$ \\
\hline
\end{tabular}

DIVA, perforated DIVerticulitis: sigmoid resection with or without Anastomosis; LOLA, LaparOscopic Lavage; HP, Hartmann procedure; SCANDIV,

SCANdinavian DIVerticulitis trial; DILALA, DIverticulitis - LAparoscopic LAvage vs. resection; DIRECT, DIverticulitis REcurrences or Continuing symptoms: operative vs. conservative Treatment; GIQLI, gastrointestinal quality of life index; LASER, LAparoscopic elective Sigmoid Resection following diverticulitis; N/A, not available

patient presentation and treatment strategies are profoundly diverse and rapidly evolving.

\section{Laparoscopic vs. open surgery for emergent cases}

A relatively more recent trend in surgical research has been questioning the appropriateness of laparoscopic sigmoid resections in emergent diverticulitis cases, as opposed to the traditional open operation. Retrospective reviews have been promising in favor of the laparoscopic approach, though these (despite attempts at propensity scoring) still suffer from the selection bias of older and more comorbid patients receiving open operations, and intention-to-treat analyses despite high conversion rates to open procedures [54-56]. No RCT has yet been performed on this topic.

\section{Damage control surgery (DCS)}

DCS is a well-established strategy, typically implemented in the setting of severe traumatic intraabdominal injuries 


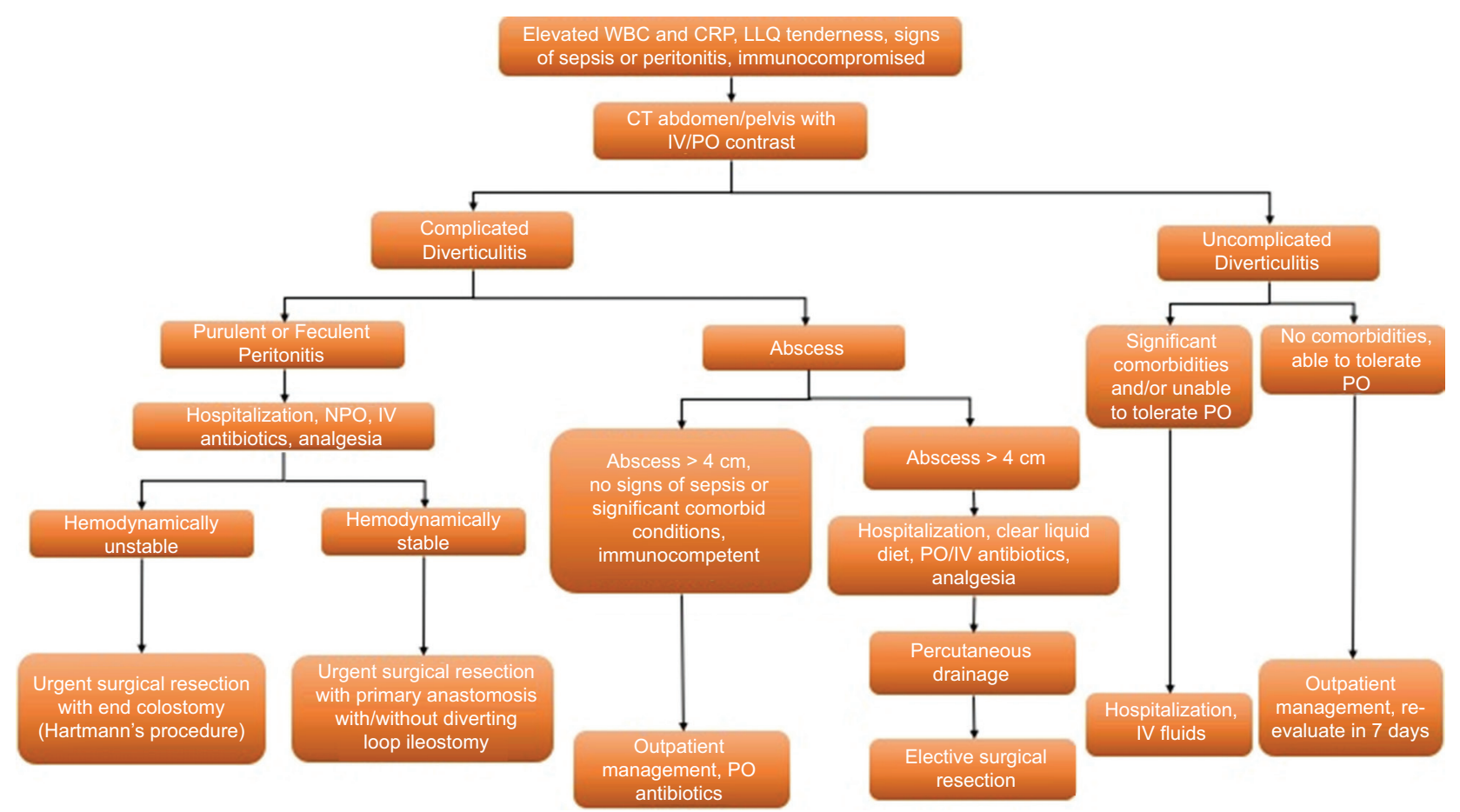

Figure 2 Management algorithm for acute diverticulitis. Management and treatment strategies depend on the severity of presentation, presence of significant comorbidities, and presence of complications (peritonitis, abscess, etc.). Recommendations based on current WSES Guidelines 2020. High-risk presentation includes elevated WBC and/or CRP, fever, signs of sepsis or peritonitis, and/or immunocompromised status. Current recommendation is to not prescribe antibiotics in uncomplicated cases in immunocompetent patients

CRP, C-reactive protein; CT, computed topography; IV, intravenous; LLQ, left lower quadrant; NPO, nil per os; PO, per os; WBC, white blood cell count; WSES, World Society of Emergency Surgery

when the patient is physiologically decompensating. There is some evidence that supports the use of this surgical strategy in non-traumatic surgical emergencies, such as perforated acute diverticulitis. DCS includes an abbreviated source-control laparotomy with a vacuum-assisted temporary abdominal closure device, followed by transfer to the Intensive Care Unit for resuscitation, with or without second-look laparotomy, and delayed definitive surgical repair [57,58]. A systematic review of 8 trials ( 7 retrospective and 1 prospective) between 2006 and 2018 evaluated the indications for and outcomes related to DCS for perforated acute diverticulitis. They found that patients treated with DCS had a lower percentage of overall morbidity, 30-day mortality, and definitive ostomy compared to those treated with Hartman's procedure [58]. Based on the 2016 WSES Guidelines, DCS remains an effective surgical strategy in critically ill patients affected by sepsis/septic shock and hemodynamic instability. RCTs are needed to refine the indications and techniques of DCS for patients with perforated acute diverticulitis.

\section{Adjunctive therapy after surgery}

Endoluminal vacuum-assisted (EVAT) therapy is a novel technique that in recent years has shown promising data supportive of improved healing rates of anastomotic leaks in high-risk low colorectal anastomoses. A polyurethane sponge is placed intraoperatively, positioned transanally at the level of the anastomosis, and then connected to a negative pressure device. Data suggest that healing rates are best when EVAT is administered early, within 10-40 days of the leak [59]. Retrospective studies have shown that EVAT is less effective without a diverting ostomy [59]. One study evaluated the use of prophylactic EVAT to prevent anastomotic leak in highrisk anastomosis in 14 patients who underwent colorectal surgery [60]. In only one of these patients was the surgical indication perforated diverticulitis. They found successful prevention of anastomotic leak in 13 of 14 (92\%) patients. This study was limited by the small number of patients and the lack of comparison to the standard of care. Currently, the data regarding EVAT for high-risk anastomosis are limited; however, it seems to be a safe and effective technique with successful healing rates quoted as up to $75 \%[60,61]$. Further prospective randomized trials are required to establish the role of EVAT for high-risk anastomosis after colorectal surgery.

Fibrin glue is often used in the management of anal fistulas, but there have been some examples in the literature of its use in enterocutaneous (EC) fistulas. EC fistulas are not an uncommon complication after a Hartmann's procedure for complicated diverticulitis. Data on fibrin glue used to treat EC fistulas is scarce, but the glue is often administered endoscopically. Fibrin glue has been most extensively studied in small-bowel EC fistulas and appears to be most effective in low-output fistulas with long, narrow tracts [62]. At present, 
the role of fibrin glue in complicated diverticulitis complicated by fistula is unknown and requires further study.

\section{Elective operative management of diverticulitis}

The debate surrounding the need for elective resection following a single uncomplicated episode of diverticulitis has died down; no guidelines recommend this routine practice and its frequency is decreasing [63]. However, there may be a benefit to elective resection in the setting of multiple/recurrent episodes, a complicated episode, or in the case of smoldering disease.

The DIRECT trial evaluated gastrointestinal quality of life at 6 months in an RCT of Dutch patients with uncomplicated or complicated recurrent $(>2$ episodes in 2 years), or smoldering disease, assigned to elective resection or conservative management [64]. The authors found a significant improvement in gastrointestinal quality of life in the resection group, and reported that a quarter of the patients in the conservative management group ended up opting for a resection by 6 months and nearly half at 5 years. Additionally, at 5 years, these improvements in quality of life may persist, and the elective resection approach may also be more cost effective $[65,66]$. A similar, more recent publication, the LASER trial of Finnish patients, published essentially identical findings from their own RCT [67]. Both studies, as would be expected, noted higher rates of anastomotic leakage and major complications in the surgery group. Findings of these trials are summarized in Table 1.

Additional retrospective reviews have supported improved quality-of-life measures with elective resections, particularly for more complicated stages of disease, with one study suggesting the greatest emotional quality of life improvement in women undergoing laparoscopic resection [68-70].

\section{Colonoscopy following diverticulitis}

The premise that patients with diverticulitis should be evaluated via endoscopy to rule out CRC is generally accepted; however, the timing and frequency of endoscopy is still subject to much discussion. Is any endoscopy within the recommending screening interval for a patient adequate, or should each episode of diverticulitis be followed up with additional endoscopy? A recent 2019 meta-analysis of 17 studies found a $6.7 \%$ rate of advanced neoplasia and a $2.1 \%$ prevalence of CRC in those undergoing colonoscopy within 1 year of left-sided diverticulitis [71]. Importantly, in the subgroup of those with uncomplicated diverticulitis, the prevalence of CRC was just $0.5 \%$, leading the authors to conclude that routine colonoscopy may be omitted for those with uncomplicated diverticulitis in the presence of an otherwise normal computed tomography scan. A similar meta-analysis of 31 studies published in the same year found a pooled prevalence of CRC of $7.9 \%$ in complicated diverticulitis and $1.3 \%$ in uncomplicated disease [72]. Other recent smaller institutional reviews have demonstrated similar findings [73-75].
In contrast, an institutional study of over 5000 patients found a higher risk of CRC in all those with diverticulitis that was not lessened by an uncomplicated episode [76]. An additional national database study found that the risk of CRC diagnosis after first-ever acute diverticulitis was particularly high in women, African Americans, and adults aged 1865 years, though this study was unable to stratify risk based on complicated vs. uncomplicated disease [77]. A Singaporean study raised similar concerns that the risk of CRC, even in uncomplicated diverticulitis, may not be as low as previously thought [78]. Therefore, on this topic, the jury is still out.

\section{Concluding remarks}

From honing in on specific dietary and genetic associations to refining surgical techniques, the complex landscape of diverticulitis is ever-changing. At a glance, there are more publications on quality of life and cost-effectiveness outcomes. These matters are particularly important as we attempt to become less aggressive in our care, so that we do not inadvertently promote chronic symptoms and recurrent disease in the name of "doing less". Patterns of treatment and societal guidelines remain significantly heterogeneous worldwide. We look forward to the longer-term results of trials from the last decade and ongoing innovation in the field.

\section{References}

1. Ma W, Nguyen LH, Song M, et al. Intake of dietary fiber, fruits, and vegetables and risk of diverticulitis. Am J Gastroenterol 2019;114:1531-1538.

2. Strate LL, Keeley BR, Cao Y, Wu K, Giovannucci EL, Chan AT. Western dietary pattern increases, and prudent dietary pattern decreases, risk of incident diverticulitis in a prospective cohort study. Gastroenterology 2017;152:1023-1030.

3. Cao Y, Strate LL, Keeley BR, et al. Meat intake and risk of diverticulitis among men. Gut 2018;67:466-472.

4. Ma W, Jovani M, Nguyen LH, et al. Association between inflammatory diets, circulating markers of inflammation, and risk of diverticulitis. Clin Gastroenterol Hepatol 2020;18:2279-2286.

5. Gayam V, Koirala S, Garlapati PR, Mandal AK. Outcomes of diverticulitis in patients with tobacco smoking: a propensitymatched analysis of nationwide inpatient sample. Int J Colorectal Dis 2021;36:1033-1042.

6. Ma W, Jovani M, Liu PH, et al. Association between obesity and weight change and risk of diverticulitis in women. Gastroenterology 2018;155:58-66.

7. Liu PH, Cao Y, Keeley BR, et al. Adherence to a healthy lifestyle is associated with a lower risk of diverticulitis among men. Am J Gastroenterol 2017;112:1868-1876.

8. Adler JT, Chang DC, Chan AT, Faiz O, Maguire LH. Seasonal variation in diverticulitis: evidence from both hemispheres. Dis Colon Rectum 2016;59:870-877.

9. Strate LL, Erichsen R, Baron JA, et al. Heritability and familial aggregation of diverticular disease: a population-based study of twins and siblings. Gastroenterology 2013;144:736-742.

10. Granlund J, Svensson T, Olén O, et al. The genetic influence on 
diverticular disease-a twin study. Aliment Pharmacol Ther 2012;35:1103-1107.

11. Broad JB, Wu Z, Clark TG, et al. Diverticulosis and nine connective tissue disorders: epidemiological support for an association. Connect Tissue Res 2019;60:389-398.

12. Coble JL, Sheldon KE, Yue F, et al. Identification of a rare LAMB4 variant associated with familial diverticulitis through exome sequencing. Hum Mol Genet 2017;26:3212-3220.

13. Connelly TM, Berg AS, Hegarty JP, et al. The TNFSF15 gene single nucleotide polymorphism rs7848647 is associated with surgical diverticulitis. Ann Surg 2014;259:1132-1137.

14. Sigurdsson S, Alexandersson KF, Sulem P, et al. Sequence variants in ARHGAP15, COLQ and FAM155A associate with diverticular disease and diverticulitis. Nat Commun 2017;8:15789.

15. Schafmayer C, Harrison JW, Buch S, et al. Genome-wide association analysis of diverticular disease points towards neuromuscular, connective tissue and epithelial pathomechanisms. Gut 2019;68:854-865.

16. Maguire LH, Handelman SK, Du X, Chen Y, Pers TH, Speliotes EK. Genome-wide association analyses identify 39 new susceptibility loci for diverticular disease. Nat Genet 2018;50:1359-1365.

17. Almalki T, Garfinkle R, Kmiotek E, et al. Family history is associated with recurrent diverticulitis after an episode of diverticulitis managed nonoperatively. Dis Colon Rectum 2020;63:944-954.

18. Chabok A, Påhlman L, Hjern F, Haapaniemi S, Smedh K; AVOD Study Group. Randomized clinical trial of antibiotics in acute uncomplicated diverticulitis. Br J Surg 2012;99:532-539.

19. Isacson D, Smedh K, Nikberg M, Chabok A. Long-term followup of the AVOD randomized trial of antibiotic avoidance in uncomplicated diverticulitis. Br J Surg 2019;106:1542-1548.

20. Daniels L, Ünlü, de Korte N, et al; Dutch Diverticular Disease (3D) Collaborative Study Group. Randomized clinical trial of observational versus antibiotic treatment for a first episode of CTproven uncomplicated acute diverticulitis. Br J Surg 2017;104:52-61.

21. van Dijk ST, Daniels L, Ünlü, et al; Dutch Diverticular Disease (3D) Collaborative Study Group. Long-term effects of omitting antibiotics in uncomplicated acute diverticulitis. Am J Gastroenterol 2018;113:1045-1052.

22. Francis NK, Sylla P, Abou-Khalil M, et al. EAES and SAGES 2018 consensus conference on acute diverticulitis management: evidence-based recommendations for clinical practice. Surg Endosc 2019;33:2726-2741.

23. Dahl C, Crichton M, Jenkins J, et al. Evidence for dietary fibre modification in the recovery and prevention of reoccurrence of acute, uncomplicated diverticulitis: a systematic literature review. Nutrients 2018;10:137.

24. Bianchi M, Festa V, Moretti A, et al. Meta-analysis: long-term therapy with rifaximin in the management of uncomplicated diverticular disease. Aliment Pharmacol Ther 2011;33:902-910.

25. Moniuszko A, Rydzewska G. The effect of cyclic rifaximin therapy on symptoms of diverticular disease from the perspective of the gastroenterology outpatient clinic: a "real-life" study. Prz Gastroenterol 2017;12:145-151.

26. Carter F, Alsayb M, Marshall JK, Yuan Y. Mesalamine (5-ASA) for the prevention of recurrent diverticulitis. Cochrane Database Syst Rev 2017;10:CD009839.

27. Khan RMA, Ali B, Hajibandeh S, Hajibandeh S. Effect of mesalazine on recurrence of diverticulitis in patients with symptomatic uncomplicated diverticular disease: a meta-analysis with trial sequential analysis of randomized controlled trials. Colorectal Dis 2018;20:469-478.

28. Iannone A, Ruospo M, Wong G, et al. Mesalazine for people with diverticular disease: a systematic review of randomized controlled trials. Can J Gastroenterol Hepatol 2018;2018:5437135.

29. Picchio M, Elisei W, Brandimarte G, et al. Mesalazine for the treatment of symptomatic uncomplicated diverticular disease of the colon and for primary prevention of diverticulitis: a systematic review of randomized clinical trials. J Clin Gastroenterol 2016;50 (Suppl 1):S64-S69.

30. Lahner E, Bellisario C, Hassan C, Zullo A, Esposito G, Annibale B. Probiotics in the treatment of diverticular disease. a systematic review. J Gastrointestin Liver Dis 2016;25:79-86.

31. Banasiewicz T, Francuzik W, Bobkiewicz A, et al. The influence of rifaximin on diverticulitis rate and quality of life in patients with diverticulosis. Pol Przegl Chir 2017;89:22-31.

32. Cirocchi R, Randolph JJ, Binda GA, et al. Is the outpatient management of acute diverticulitis safe and effective? A systematic review and meta-analysis. Tech Coloproctol 2019;23:87-100.

33. van Dijk ST, Bos K, de Boer MGJ, et al. A systematic review and meta-analysis of outpatient treatment for acute diverticulitis. Int $J$ Colorectal Dis 2018;33:505-512.

34. Joliat GR, Emery J, Demartines N, Hübner M, Yersin B, Hahnloser D. Antibiotic treatment for uncomplicated and mild complicated diverticulitis: outpatient treatment for everyone. Int $J$ Colorectal Dis 2017;32:1313-1319.

35. Sirany AE, Gaertner WB, Madoff RD, Kwaan MR. Diverticulitis diagnosed in the emergency room: is it safe to discharge home? J Am Coll Surg 2017;225:21-25.

36. Lamb MN, Kaiser AM. Elective resection versus observation after nonoperative management of complicated diverticulitis with abscess: a systematic review and meta-analysis. Dis Colon Rectum 2014;57:1430-1440.

37. von Strauss Und Torney M, Moffa G, Kaech M, et al. Risk of emergency surgery or death after initial nonoperative management of complicated diverticulitis in Scotland and Switzerland. JAMA Surg 2020;155:600-606.

38. Lambrichts DPV, Vennix S, Musters GD, et al; LADIES trial collaborators. Hartmann's procedure versus sigmoidectomy with primary anastomosis for perforated diverticulitis with purulent or faecal peritonitis (LADIES): a multicentre, parallel-group, randomised, open-label, superiority trial. Lancet Gastroenterol Hepatol 2019;4:599-610.

39. Acuna SA, Dossa F, Baxter NN. The end of the Hartmann's era for perforated diverticulitis. Lancet Gastroenterol Hepatol 2019;4:573-575.

40. Lambrichts DPV, van Dieren S, Bemelman WA, Lange JF. Costeffectiveness of sigmoid resection with primary anastomosis or end colostomy for perforated diverticulitis: an analysis of the randomized Ladies trial. Br J Surg 2020;107:1686-1694.

41. Cauley CE, Patel R, Bordeianou L. Use of primary anastomosis with diverting ileostomy in patients with acute diverticulitis requiring urgent operative intervention. Dis Colon Rectum 2018;61:586-592.

42. Vennix S, Musters GD, Mulder IM, et al; Ladies trial colloborators. Laparoscopic peritoneal lavage or sigmoidectomy for perforated diverticulitis with purulent peritonitis: a multicentre, parallelgroup, randomised, open-label trial. Lancet 2015;386:1269-1277.

43. Angenete E, Thornell A, Burcharth J, et al. Laparoscopic lavage is feasible and safe for the treatment of perforated diverticulitis with purulent peritonitis: the first results from the randomized controlled trial DILALA. Ann Surg 2016;263:117-122.

44. Schultz JK, Yaqub S, Wallon C, et al; SCANDIV Study Group. Laparoscopic lavage vs primary resection for acute perforated diverticulitis: the SCANDIV randomized clinical trial. JAMA 2015;314:1364-1375.

45. Azhar N, Johanssen A, Sundström T, et al; SCANDIV Study Group. Laparoscopic lavage vs primary resection for acute perforated diverticulitis: long-term outcomes from the Scandinavian diverticulitis (SCANDIV) randomized clinical trial. JAMA Surg 2021;156:121-127.

46. Thornell A, Angenete E, Bisgaard T, et al. Laparoscopic lavage for perforated diverticulitis with purulent peritonitis: a randomized 
trial. Ann Intern Med 2016;164:137-145.

47. Gehrman J, Angenete E, Björholt I, Bock D, Rosenberg J, Haglind E. Health economic analysis of laparoscopic lavage versus Hartmann's procedure for diverticulitis in the randomized DILALA trial. $\mathrm{Br} J$ Surg 2016;103:1539-1547.

48. Kohl A, Rosenberg J, Bock D, et al. Two-year results of the randomized clinical trial DILALA comparing laparoscopic lavage with resection as treatment for perforated diverticulitis. Br J Surg 2018; 105:1128-1134.

49. Angenete E, Bock D, Rosenberg J, Haglind E. Laparoscopic lavage is superior to colon resection for perforated purulent diverticulitis-a meta-analysis. Int J Colorectal Dis 2017;32:163-169.

50. Cirocchi R, Di Saverio S, Weber DG, et al. Laparoscopic lavage versus surgical resection for acute diverticulitis with generalised peritonitis: a systematic review and meta-analysis. Tech Coloproctol 2017;21:93-110.

51. Penna M, Markar SR, Mackenzie H, Hompes R, Cunningham C. Laparoscopic lavage versus primary resection for acute perforated diverticulitis: review and meta-analysis. Ann Surg 2018;267:252-258.

52. Galbraith N, Carter JV, Netz U, et al. Laparoscopic lavage in the management of perforated diverticulitis: a contemporary metaanalysis. J Gastrointest Surg 2017;21:1491-1499.

53. Acuna SA, Wood T, Chesney TR, et al. Operative strategies for perforated diverticulitis: a systematic review and meta-analysis. Dis Colon Rectum 2018:61:1442-1453.

54. Lee YF, Brown RF, Battaglia M, Cleary RK. Laparoscopic versus open emergent sigmoid resection for perforated diverticulitis. J Gastrointest Surg 2020;24:1173-1182.

55. Vennix S, Lips DJ, Di Saverio S, et al. Acute laparoscopic and open sigmoidectomy for perforated diverticulitis: a propensity scorematched cohort. Surg Endosc 2016;30:3889-3896.

56. Esparza Monzavi CA, Naffouje SA, Chaudhry V, Nordenstam J, Mellgren A, Gantt G Jr. Open vs minimally invasive approach for emergent colectomy in perforated diverticulitis. Dis Colon Rectum 2021;64:319-327.

57. Kafka-Ritsch R, Birkfellner F, Perathoner A, et al. Damage control surgery with abdominal vacuum and delayed bowel reconstruction in patients with perforated diverticulitis Hinchey III/IV. J Gastrointest Surg 2012;16:1915-1922.

58. Zizzo M, Castro Ruiz C, Zanelli M, et al. Damage control surgery for the treatment of perforated acute colonic diverticulitis: A systematic review. Medicine (Baltimore) 2020;99:e23323.

59. Popivanov GI, Mutafchiyski VM, Cirocchi R, et al. Endoluminal negative pressure therapy in colorectal anastomotic leaks. Colorectal Dis 2020;22:243-253.

60. Lehwald-Tywuschik NC, Alexander A, Alkhanji N, et al. The "impossible" rectal anastomosis: a novel use for endoluminal vacuum-assisted therapy. Tech Coloproctol 2021;25:125-130.

61. van Koperen PJ, van Berge Henegouwen MI, Rosman C, et al. The Dutch multicenter experience of the endo-sponge treatment for anastomotic leakage after colorectal surgery. Surg Endosc 2009;23:1379-1383.

62. Draus JM Jr, Huss SA, Harty NJ, Cheadle WG, Larson GM. Enterocutaneous fistula: are treatments improving? Surgery 2006;140:570-576.

63. Li D, Baxter NN, McLeod RS, Moineddin R, Nathens AB. The decline of elective colectomy following diverticulitis: a populationbased analysis. Dis Colon Rectum 2016;59:332-339.

64. van de Wall BJM, Stam MAW, Draaisma WA, et al; DIRECT trial collaborators. Surgery versus conservative management for recurrent and ongoing left-sided diverticulitis (DIRECT trial): an open-label, multicentre, randomised controlled trial. Lancet Gastroenterol Hepatol 2017;2:13-22.

65. Patel SV, Hendren S, Zaborowski A, Winter D; for Members of the Evidence Based Reviews in Surgery group. Evidencebased reviews in surgery long-term outcome of surgery versus conservative management for recurrent and ongoing complaints after an episode of diverticulitis: five-year follow-up results of a multicenter randomized controlled trial (DIRECT-trial). Ann Surg 2020;272:284-287.

66. Bolkenstein HE, de Wit GA, Consten ECJ, Van de Wall BJM, Broeders IAMJ, Draaisma WA. Cost-effectiveness analysis of a multicentre randomized clinical trial comparing surgery with conservative management for recurrent and ongoing diverticulitis (DIRECT trial). Br J Surg 2019;106:448-457.

67. Santos A, Mentula P, Pinta T, et al. Comparing laparoscopic elective sigmoid resection with conservative treatment in improving quality of life of patients with diverticulitis: the laparoscopic elective sigmoid resection following diverticulitis (LASER) randomized clinical trial. JAMA Surg 2021;156:129-136.

68. Justin V, Uranues S, Rabl H, Fingerhut A. Quality of life in uncomplicated recurrent diverticulitis: surgical vs. conservative treatment. Sci Rep 2020;10:10261.

69. Brandlhuber M, Genzinger C, Brandlhuber B, Sommer WH, Müller MH, Kreis ME. Long-term quality of life after conservative treatment versus surgery for different stages of acute sigmoid diverticulitis. Int J Colorectal Dis 2018;33:317-326.

70. Polese L, Bressan A, Savarino E, et al. Quality of life after laparoscopic sigmoid resection for uncomplicated diverticular disease. Int J Colorectal Dis 2018;33:513-523.

71. Rottier SJ, van Dijk ST, van Geloven AAW, et al. Meta-analysis of the role of colonoscopy after an episode of left-sided acute diverticulitis. Br J Surg 2019;106:988-997.

72. Meyer J, Orci LA, Combescure C, et al. Risk of colorectal cancer in patients with acute diverticulitis: a systematic review and meta-analysis of observational studies. Clin Gastroenterol Hepatol 2019;17:1448-1456.

73. Andrade P, Ribeiro A, Ramalho R, Lopes S, Macedo G. Routine colonoscopy after acute uncomplicated diverticulitis - challenging a putative indication. Dig Surg 2017;34:197-202.

74. Abu Baker F, Ganayem M, Mari A, Taher R, Suki M, Kopelman Y. Acute complicated diverticulitis is associated with an increased advanced neoplasia diagnosis rate: A retrospective study on 1852 patients. Medicine (Baltimore) 2021;100:e24271.

75. Abdulazeez Z, Kukreja N, Qureshi N, Lascelles S. Colonoscopy and flexible sigmoidoscopy for follow-up of patients with left-sided diverticulitis. Ann R Coll Surg Engl 2020;102:744-747.

76. Tehranian S, Klinge M, Saul M, Morris M, Diergaarde B, Schoen RE. Prevalence of colorectal cancer and advanced adenoma in patients with acute diverticulitis: implications for follow-up colonoscopy. Gastrointest Endosc 2020;91:634-640.

77. Jin-Dominguez F, Mansoor E, Panhwar MS, et al. Epidemiology of diverticulitis and prevalence of first-ever colorectal cancer postdiverticulitis in adults in the United States: a population-based national study. Dis Colon Rectum 2021;64:181-189.

78. Soh NYT, Chia DKA, Teo NZ, Ong CJM, Wijaya R. Prevalence of colorectal cancer in acute uncomplicated diverticulitis and the role of the interval colonoscopy. Int J Colorectal Dis 2018;33:991-994. 